\title{
DESIGNING MOBILE-BASED IMNCI APP FOR FRONTLINE HEALTH WORKERS IN A TRIBAL SETTING OF GUJARAT, INDIA: ROLE OF USER RESEARCH
}

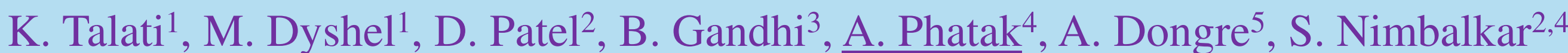

${ }^{1}$ Department of Interdisciplinary Research, Foundation for Diffusion of Innovations, Vadodara

${ }^{2}$ Department of Pediatrics, Pramukh Swami Medical College and Shree Krishna Hospital, Karamsad

${ }^{3}$ Department of Tribal Initiatives, Foundation for Diffusion of Innovations, Dahod

${ }^{4}$ Central Research Services, Charutar Arogya Mandal, Karamsad

${ }^{5}$ Department of Community Medicine, Sri ManakulaVinayagar Medical College and Hospital, Puducherry

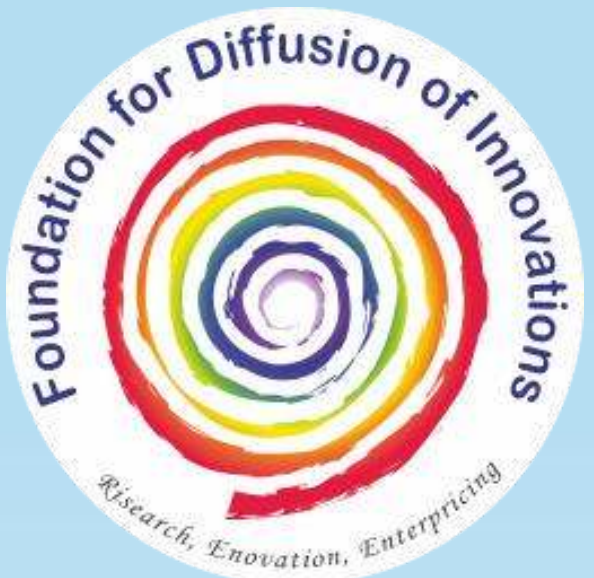

\section{Background}

$\square$ In case of Integrated Management of Neonatal and Childhood Illnesses (IMNCI), where the clinical guidelines and scope of service providers is well-defined, it allows an opportunity to translate it into point-of-care clinical decision support system.

$\square$ Backed by increasing penetration of mobile internet, such an advent could help frontline health workers better assess in fields, provide appropriate care and reduce unnecessary referrals.

\section{Aim}

$\square$ The scope of this research was usability and feasibility testing of the IMNCI mobile application to be developed based on the human-centered design approach and sound understanding of user group requirements.

\section{Methodology}

\section{$\square$ The user research included}

i. Field observations of the frontline health workers (FHWs) - performing IMNCI assessment,

ii. Face-to-face interviews, and

iii. Analysis of IMNCI reporting format.

$\square$ The observations and interviews covered different contexts of home-based newborn care visits, the reporting process and its impact on the worker, the needs of the workers and their acquaintance with mobile technology.

\section{$\square$ User feedback on paper prototype and computer-based} wireframes about the main flow of the app was sought from primary users before formative usability tests.

\section{Results}

$\square$ The user research yielded significant findings that helped to shape the functionality of the application, as well as its user interface.

$\square$ We found out that other workers in the primary healthcare center ecosystem can also use the application, but for different purposes: some of them, such as

i. Multi-purpose healthcare workers (MPHWs) can use it to assist the FHWs in the field;

ii. Medical officers and supervisors, may need it to receive timely information about the case statistics.
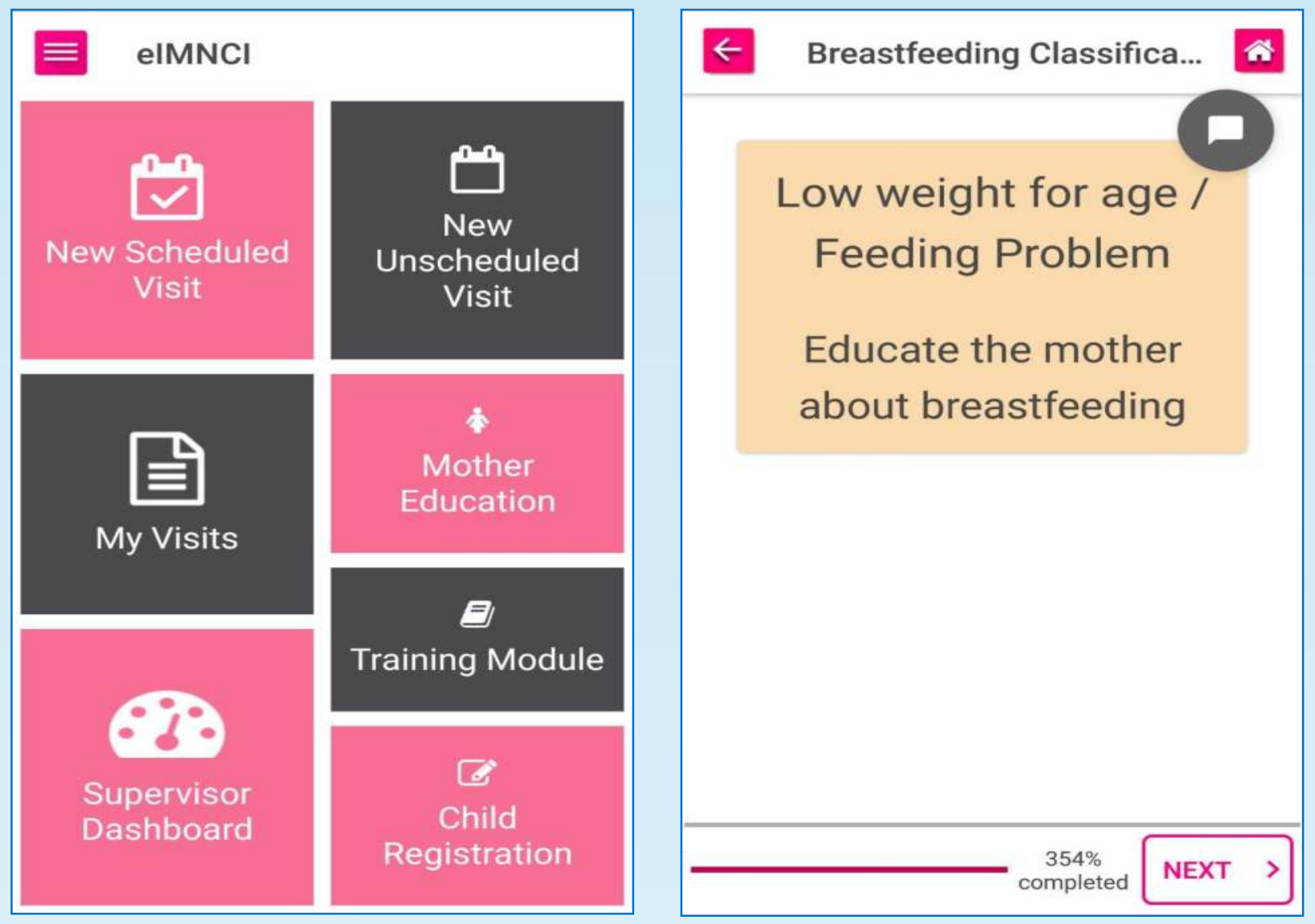

IMNCI Mobile App

Home Page

IMNCI Mobile App

\section{Classification Screen}

\section{Conclusion}

$\square$ Human-centered design approach provides opportunity for designing app that will be easy to use even for those among FHWs/MPHWs who are new to smart phone technology.

$\square$ It could also help minimize mechanical component of healthcare reporting to improve the data and supervision quality, data analytics, dashboard reporting and dissemination. 